\title{
Bone marrow derived CD 34+ cells and leukocytes in 729 children and adults with non-malignant diseases
}

\section{Christof Pabinger}

Institute for Regenerative Medicine (IRM) and Medical University of Innsbruck https://orcid.org/00000003-4622-9399

\section{Brenda Laky}

Austrian Society for Regenerative Medicine and Austrian Research group for Regenerative and Orthopedic Medicine (AURROM)

\section{Philip Heuberer}

Austrian Research group for Regenerative and Orthopedic Medicine (AURROM) and OrthoCare and HealthPi Medical Center

Georg Stefan Kobinia ( $\nabla$ georg.kobinia@sct-vienna.com )

Institute for Regenerative Medicine Graz and Austrian Society of Regenerative Medicine

\section{Research}

Keywords: bone marrow (BM), CD34+ cells, leukocytes, age, children and adults

Posted Date: February 22nd, 2021

DOl: https://doi.org/10.21203/rs.3.rs-70184/v2

License: (9) This work is licensed under a Creative Commons Attribution 4.0 International License. Read Full License 


\section{Bone marrow derived CD 34+ cells and leukocytes in 729}

\section{2 children and adults with non-malignant diseases}

4 Running title: CD34+ cells in non-malignant children and adults

5

6 Christof Pabinger, $\mathrm{MD}^{1,2}$, Brenda Laky, MSc, $\mathrm{PhD}^{3,4}$, Philipp R. Heuberer ${ }^{4,5}$, Georg S.

7 Kobinia, $\mathrm{MD}^{1,3^{*}}$

8

$9 \quad{ }^{1}$ Institute for Regenerative Medicine (IRM), Graz, Austria

$10 \quad{ }^{2}$ Medical University of Innsbruck, Innsbruck, Austria

$11{ }^{3}$ Austrian Society of Regenerative Medicine, Vienna, Austria

$12{ }^{4}$ Austrian Research group for Regenerative and Orthopedic Medicine (AURROM), Vienna,

13 Austria

$14{ }^{5}$ OrthoCare and HealthPi Medical Center, Vienna, Austria

15

16

17

* Correspondence:

Doz. George S. Kobinia, MD

Fax: +4314700 499 


\section{Author contributions:}

Christof Pabinger: Conception and design, manuscript writing, and final approval of manuscript

Brenda Laky: Collection and/or assembly of data, data analysis and interpretation, manuscript writing, and final approval of manuscript Philipp R. Heuberer: Manuscript writing and final approval of manuscript Georg S. Kobinia: Conception and design, provision of study material or patients (As an experienced general and cardiac surgeon, he performed all stem cell procedures), collection and/or assembly of data, data analysis and interpretation, and final approval of manuscript

\section{ACKNOWLEDGEMENTS}

Thanks to Harald Lothaller, Sandra Gieringer und Marcel Krall for drafting preliminary statistical analysis.

\section{Disclosure of Potential Conflicts of Interest}

The authors declare no potential conflict of interest.

\section{Data Availability Statement}

The data that support the findings of this study are available from the corresponding author upon reasonable request.

Funding: No funding received.

KEYWORDS: bone marrow (BM), CD34+ cells, leukocytes, age, children and adults 


\section{Significance statement}

60 With the present study, we are reporting CD34+ cells and leukocytes counts in bone marrow 61 aspirate in a large number of patients who underwent autologous stem cell transplantation for standard values.

66 


\section{ABSTRACT}

70 To our knowledge, no large studies reporting bone marrow (BM) derived cell counts of children and adults with non-malignant diseases have been published so far. Thus, the primary objective was to evaluate BM-derived CD34+ and leukocyte cell counts in 729 female and male patients of different age groups who underwent autologous cell-based therapy for non-malignant diseases.

For this study, a retrospective data analysis of laboratory parameters including BM-aspirated and post-centrifuge concentrated CD34+ cells and leukocytes was performed. Associations and differences of cell counts between age groups, gender, and diagnose related group were evaluated.

Included were data of 187 female and 542 male patients aged between 2 and 75 years, who underwent autologous cell-based therapy for various non-malignant diseases. The median percentage of $\mathrm{CD}_{3} 4^{+}$cells of leukocytes was $1.10 \%$ in BM-aspirate (BMA) and $0.96 \%$ in post-centrifuge BMA concentrate (BMAC). Significant moderate positive correlations were observed between CD34+ cells (count/ $\mu \mathrm{l})$ and leukocytes (count $/ \mu \mathrm{l})$ in BMA and in BMAC. Significant strong negative correlations were detected between age (years) and CD34+ cells (count $/ \mu 1 / \mathrm{kg}$ ) in BMA and in BMAC. No significant differences regarding CD34+ cells (count/ $\mu 1$ ) in BMA were detected between adults, while significant differences regarding cell counts were detected between diagnose related groups, but not between females and males. This study including 729 patients with various non-malignant diseases showed that approximately $1 \%$ of leukocytes were CD34+ cells in BMA and in BMAC. While BM-

90 derived CD34+ cells were significantly higher in younger patients, similar cell counts were detected within adults. 


\section{INTRODUCTION}

In the past decade, bone marrow (BM)-derived cell-based therapies have been performed in various fields of regenerative medicine. In spite of the fact that BM contains hematopoietic stem cells, the CD34+ cells are an essential part in therapy and are known as indirect indicators for progenitor cells and thus, are considered as the gold standard for stem cell quantifications. ${ }^{1}$ Yet, little is known about standard values of these cells in the BM. CD34+ cell counts are still not routinely reported in therapeutic studies with autologous BM. Thus, crucial knowledge of what we are doing in regenerative medicine is at least in part lacking. The reason for this discrepancy may be that hematooncologist, who have the best knowledge in BM physiology, rarely engage in regenerative medicine, while on the other side, specialists (mainly surgeons) engaged in regenerative medicine have little access to hematology.

Flow cytometry analysis for quantifying single-cells such as the hematopoietic surface marker CD34 has been widely used in clinical practice, especially in peripheral blood of patients with malignant diseases. ${ }^{2}$ To our knowledge, comprehensive studies reporting on typical amounts of CD34+ cells in BM are sparse. Sutherland et al. ${ }^{3}$ stated that approximately a range of 1 to $3 \%$ of BM cells express CD34+ antigen (without reporting a sample size) and Brooimans et al. $^{4}$ detected $1.4 \%$ of CD34+ in BM-aspirate (BMA) in a small series of patients.

Stem cell counts are important, since it is assumed that better clinical results can be achieved with a higher donor-site stem cell count. ${ }^{5}$ The volume of a graft required for hematopoietic stem cell transplantation is commonly based on either the number of CD34+ cells or the number of total nucleated BM cells. ${ }^{6}$

Furthermore, the impact of age is well documented for cell-based procedures, but controversial. On the one hand, grafts from older donors did not adversely affect outcomes of allogeneic hematopoietic cell transplantation as compared to grafts from younger donors in hematooncology, while on the other hand, lower CD34+ cell counts were reported in older donors, ${ }^{7-9}$ and older age correlated with inferior results ${ }^{10}$ or lower CD34+ cell counts in some 
specific diagnoses. ${ }^{11}$ Thus, it seems clear that BM cell counts are deteriorating with increased

120 age. However, the majority of studies reported data of patients with malignant diseases or

121 their healthy donors, ${ }^{6-8,10}$ but little is known about patients with non-malignant pathologies.

122 With the present study, we are reporting counts of CD34+ cells and leukocytes in BMA and

123 centrifuged BMA-concentrate (BMAC) in a large number of patients who underwent

124 autologous stem cell transplantation for various non-malignant diseases. Cell counts were

125 analyzed regarding influences of age, gender and diagnose related groups.

\section{MATERIALS AND METHODS}

128 For this retrospective study, all laboratory data of patients who underwent stem cell

129 transplantation for non-malignant diseases up to 2019 were evaluated. The respective

130 diagnoses of patients treated at the institute for regenerative medicine were spinal cord injury,

131 amyotrophic lateral sclerosis, autism, cerebral palsy, neurodegenerative diseases (e.g. multiple

132 sclerosis, Parkinson, ataxia), muscle dystrophy, and neurological diseases (e.g. traumatic

133 brain injury, stroke). Included were female and male patients aged between 2 and 75 years

134 with available BM-derived $\mathrm{CD} 34^{+}$cells (count $/ \mu 1$ and count $/ \mu 1 / \mathrm{kg}$ body weight) and

135 leukocytes (count $/ \mu \mathrm{l}$ and cells $/ \mu \mathrm{l} / \mathrm{kg}$ body weight) of the BMA and post-centrifuged BMAC.

136 Percentages of $\mathrm{CD} 34^{+}$cells of leukocytes and concentrations of BMAC of BMA were

137 calculated. Data from procedures with missing or invalid cell counts were excluded. The

138 study was approved by the ethics committee of the Medical University of Graz (31-152 ex

139 18/19, Ethikkommission der Medizinischen Universität Graz, Auenbruggerplatz 2, 1.OG,

1408036 Graz, Austria / EU). All methods were carried out in accordance with relevant

141 guidelines and regulations.

142 All procedures were performed as point-of-care method in a laminar air flow operating room.

143 Aspiration of BM was performed by the same experienced surgeon (G.S.K.) from the

144 posterior and anterior iliac crest. Stem cells were harvested with a Yamshidi Needle (15ga x 
146 under sedoanalgesia. BMA was retrieved using $10 \mathrm{ml}$ syringes and changing direction

147 repeatedly as published by Oliver et al. ${ }^{12}$. Following, BMA was processed in the operating

148 room according to the SmartRedux protocol (Biosafe, Eysins, Switzerland) using a fully

149 automated cell separator (Sepax ${ }^{\circledR}$ S-100; Biosafe, Eysins, Switzerland).

150 One $\mathrm{ml}$ of the total BMA sample was immediately transferred to the same laboratory and

151 analyzed with fluorescence activated cell sorter (FACS) using a stem cell kit from Beckman

152 Coulter and the ISHAGE protocol (https://www.bc-

153 cytometry.com/PDF/DataSheet/IM3630.pdf).

\section{Statistical analyses}

156 Demographic details were presented using descriptive statistics. Data distribution was

157 assessed by visual inspection of histograms and the Kolmogorov-Smirnov test. Qualitative

158 data were expressed by numbers and percentages and quantitative data as means with

159 standard deviation or median with range. CD34+ concentrations (in times) after centrifugation

160 were calculated as CD34+ cells (count/ $\mu \mathrm{l})$ in BMAC divided by CD34+ cells (count/ $\mu \mathrm{l})$ in

161 BMAC. For continuous and normal distributed data, independent t-tests were applied and

162 Mann-Whitney U or Kruskal-Wallis tests were used for non-parametric data to determine

163 differences between two or more groups, respectively. Bonferroni adjustments served for

164 multiple testing. Spearman's rank correlation coefficients (rho) were used to assess the

165 correlation between parameters. Statistical significance level was set at $P<.05$ (2-sided).

166 Statistical analyses were performed using SPSS Statistics 25 (IBM Corporation, Armonk,

$167 \mathrm{NY})$. 


\section{RESULTS}

172 A total of 729 laboratory datasets were evaluated. There were significantly more children

$173(\mathrm{n}=445,61.0 \%)$ than adults $(\mathrm{n}=284,39.0 \% ; \mathrm{p}<0.001)$ and males than females $(\mathrm{p}<0.001)$

174 treated with autologous stem cell transplantation. Frequencies of CD34+ cells (count/ $\mu \mathrm{l})$ and

175 leukocytes (count/ $\mu \mathrm{l})$ in BMA are presented in Supplement Figure S1 and S2. The median

176 percentage of CD34+ cells of the leukocytes in BMA as well as in BMAC was 1.1\%. All

177 demographic data are presented in Table 1.

178

$179 \mathrm{CD} 34+$ cells (count/ $\mu \mathrm{l})$ and leukocytes (count/ $\mu \mathrm{l})$ in BMA (Figure 1) and in BMAC showed 180 moderate positive correlations ( $r h o=0.687 ; \mathrm{p}<0.001$ and rho $=0.663 ; \mathrm{p}<0.001$, respectively).

182 The median percentage of CD34+ cells of the leukocytes in BMA was significantly higher in

183 children aged between 2 and 18 years $(1.38 \%$; IQR $1.03,1.77)$ than in adults $(0.62 \%$; IQR

$1840.38,0.88 ; \mathrm{p}<0.001)$. In BMAC the median percentage of CD34+ cells of the leukocytes was 185 also significantly higher in children $(1.28 \%$; IQR $0.90,1.74)$ than in adults $(0.60 \%$; IQR 0.41 , $1860.88 ; \mathrm{p}<0.001)$.

188 Very strong and strong negative correlations were detected between age (years) and CD34+ 189 cells (count $/ \mu 1 / \mathrm{kg})$ in BMA (Figure 2; rho $=-0.827, \mathrm{p}<0.001)$ and in BMAC (rho $=-0.712$, $190 \mathrm{p}<0.001$ ), respectively. The negative relationship between age (years) and CD34+ cells

191 (count $/ \mu \mathrm{l})$ in BMA (rho= $-0.601 ; \mathrm{p}<0.001)$ was moderate and weak in BMAC (rho= -0.285 ;

$192 \mathrm{p}<0.001)$. All correlations between age and cell counts are presented in Supplement Table S1. 193 
195 Comparisons between age groups, gender, and diagnose related groups regarding BMA and

196 BMAC showed significant differences between children and adults and between diagnose

197 related groups, but not between females and males (Supplement Table S2).

198 A comparison of CD34+ cells (count $/ \mu 1 / \mathrm{kg})$ in BMA between age-gender stratified groups

199 showed significant differences between girls (9.3, range 0.8-42.9) and women (1.3, range 0.3-

$2007.1 ; \mathrm{p}<0.001)$, boys (10.0, range 0.5-127.3) and men (1.0, range 0.2-7.7; $\mathrm{p}<0.001)$, as well as

201 between women and men $(\mathrm{p}=0.012)$, but not between girls and boys $(\mathrm{p}=0.513)$.

202 Comparison regarding CD34+ cells (count/ $\mu \mathrm{l})$ in BMA showed significant differences

203 between age groups ( $\mathrm{p}<0.001$ ), while no significant differences were detected between

204 adults' age groups (19-39years vs. 40-59years: $\mathrm{p}=0.326$; 19-39years vs. 60-79years: $\mathrm{p}=0.874$;

205 40-59years vs. 60-79years: $\mathrm{p}=0.999$ ).

206

207 Percentages of CD34+ cells of the leukocytes in BMA of children and adults according to

208 their non-malignant diseases are presented in Figure 3.

209

210 Density gradient separation using a centrifuge-based system showed that the lower the

211 CD34+ cells (count/ $\mu 1)$ in BMA, the higher the concentration (times) of CD34+ cells

212 (count/ $\mu \mathrm{l}$ ) in BMAC after centrifugation (Figure 4) and thus, the system was able to increase

213 the concentration of nucleated cells by a median of 4.59 (IQR 2.53, 8.85) times. Significant

214 lower median concentration increase regarding CD34+ cells was detected in children (3.82,

215 IQR 2.18, 6.81) than in adults (6.92, IQR 3.39, 13.8; $\mathrm{p}<0.001)$.

216

217

218 


\section{DISCUSSION}

220 The present study investigated leucocytes and CD34+ cell counts in BMA and BMAC in the

221 largest number of subjects with non-malignant diseases so far and included all ages ranging

222 from 2 to 75 years. One major finding of 729 cell counts was that approximately $1 \%$ of

223 leukocytes were CD34+ cells in BMA and in BMAC with slight variations according to age.

224 Second, BM-derived CD34+ cells were significantly higher in children as compared to adults,

225 whereas comparable cell counts were detected within the respective age groups of adults. Cell

226 counts were independent of gender.

227 Results of a previous study reporting only a weak inverse relationship ( $r=-0.4)$ between age

228 and the number of CD34 cells seem opposed to our findings on the first site. However, they

229 mainly included a small series of elderly patients with chronic heart failure. ${ }^{11}$ Indeed, we not

230 only reported a mix of DRGs, we also showed differences regarding various age groups in a

231 much larger sample size. Furthermore, our findings (higher cell counts in younger patients)

232 support a previous study with a smaller sample size. ${ }^{6}$

233 Autologous BM-derived cell-based therapies in regenerative medicine are on the rise. While it

234 is generally known that BMA contains a mix of nucleated cells and other biologics such as

235 growth factors and exosomes ${ }^{13}$, comprehensive information regarding normal ranges of

236 leucocytes and/or CD 34+ cell counts in BMA and BMAC in a large series of patients of all

237 age groups was missing.

238 We found a significant positive linear correlation $\left(\mathrm{CD} 34+=8.3 * 10^{-3}\right.$ leukocytes +61.2$)$

239 between $\mathrm{CD} 34+$ cells and leukocytes $(\mathrm{rho}=0.687 ; \mathrm{p}<0.001)$. This finding add further

240 knowledge to the findings of a study by Terstappen et al. ${ }^{14}(0.96 \pm 0.30 \%$ (range, $1.47-0.62 \%)$

241 in 10 adults) and Brooimans et al. ${ }^{4}(1.5 \pm 0.7 \%$ in 134 healthy donors).

242 Stem cells are mononuclear cells and therefore, a fraction of the bone marrow derived

243 leukocytes. Surprisingly, to our knowledge no prior study described the positive and strong

244 correlation between both parameters, which might be of use in future clinical practice. Since 
stem cells can only be identified using specific CD antigen sets (CD34, CD90, CD45,

$246 \mathrm{CD} 107, \ldots)$, which is costly and laborious, this correlation can be utilized, to predict the

247 amount of stem cells based on the number of bone marrow derived leukocytes alone, which is

248 much easier. As a matter of fact, only a negligible share of publications reports the absolute

249 number of stem cells used per patient. ${ }^{15}$ Using the newly described correlation, a much

250 cheaper possibility exists, to assess, if a specific patient has a high or low stem cell number. It

251 has to be assessed in the future, if patients with a higher leukocyte- and stem cell - count will

252 have better outcomes and might therefore be better suitable for stem cell operations.

253 According to our data stem cell counts do not deteriorate in adults (18-75 years); this supports

254 the work by Povsic et al. ${ }^{16}$ who reported that ageing is not associated with BM-resident

255 progenitor cell depletion (18-85 years).

256 Yet, we are unaware of any study reporting data of cell counts in children (2-18years).

257 Despite the fact that cell counts of our large group of children had several different diagnoses,

258 leucocytes and CD 34+ cell counts were significantly lower in adults. It remains speculative,

259 if the higher cell count in children is necessary for growth and differentiation up to the age of

260 puberty. However, since cell counts remained stable in adults (18-75years), increasing age

261 might not necessarily be a contraindication for autologous stem cell therapy.

262 Furthermore, lower cell counts may also be due to specific diseases, as for example reported

263 by Terstappen et al. ${ }^{14}$ reporting lower stem cell counts to be indicative for unfavorable

264 outcome.

265 It is also not clear yet, if heterogeneous clinical results are linked to heterogeneous bone

266 marrow derived stem cell counts. One could assume, that a higher yield of stem cells might

267 result in a superior clinical outcome. Anyway, the possible predictive value of stem cell

268 counts needs further investigations, especially linking donor-site cell counts to clinical

269 outcome and thus, to sort out patients with unfavorable cell counts to avoid unnecessary

270 interventions. 
271 Since the onset of regenerative medicine several centrifuges are available on the market for

272 mononuclear cell concentration. ${ }^{17,18}$ The concentration factor in our data showed a negative

273 correlation to the number of leukocytes in BMA. Thus, a higher degree of concentration is

274 found in patients with a lower bone marrow leukocyte count. This in part counteracts the

275 dilution occurring in any aspirate higher than $2 \mathrm{ml}$, which is due to the inflow of peripheral

276 blood into bone marrow during the aspiration process. ${ }^{19}$

\section{Limitations}

279 Despite the large sample size reporting cell counts, there are some limitations: Cell counts

280 were quantified at an extern laboratory and therefore, measurement accuracy could be

281 influenced by transport, however serial tests with the laboratory found no significant

282 difference between one to 12 hours of transport in ethylenediaminetetraacetic acid (EDTA)

283 tubes. Furthermore, our data are probably not comparable to individuals with other diagnoses

284 than those of our study group. Severity of illness, not reported in this study, might also

285 contribute to cell count variations and hence, can influence our data. Due to the retrospective

286 study design, we are not able to provide data on other cells (e.g. red blood cell count) nor are

287 we able to compare BM-derived cell counts with peripheral blood cells. Cell counts might

288 also be influenced by BMA volume, which we did not measure in this study. Further studies

289 of different age groups are needed (a) to evaluate typical BM-derived cell counts of

290 individuals with other diagnoses than ours, (b) to report cell count related outcome, and (c) to

291 link cell count data to epigenetic variables (e.g. smoking habits, body mass index, etc.)

292 However, this large study provides baseline data for further evaluations regarding autologous 293 BM-derived cell therapies. 
2975 CONCLUSION

298 With this study, we demonstrated in 729 patients including 445 children (2-18years) and 284

299 adults (19-75years) with various non-malignant diseases that approximately $1 \%$ of BM-

300 derived leukocytes were CD34+ cells. While BM-derived CD34+ cells were significantly

301 higher in children than in adults, comparable cell counts were detected within different age

302 groups of adults.

303

304 
3061 Sutherland, D. R., Anderson, L., Keeney, M., Nayar, R. \& Chin-Yee, I. The ISHAGE guidelines for CD34+ cell determination by flow cytometry. International Society of Hematotherapy and Graft Engineering. $J$ Hematother 5, 213-226, doi:10.1089/scd.1.1996.5.213 (1996).

3102 Nakamura, Y. et al. Impact of CD34+ pre-counting and plerixafor on autologous peripheral blood stem cell collection in Japanese university hospitals in eight years. Transfus Apher Sci 58, 102664, doi:10.1016/j.transci.2019.10.006 (2019). Sutherland, D. R., Stewart, A. K. \& Keating, A. CD34 antigen: molecular features and potential clinical applications. Stem Cells 11 Suppl 3, 50-57,

3164 Brooimans, R. A. et al. Flow cytometric differential of leukocyte populations in normal bone marrow: influence of peripheral blood contamination. Cytometry B Clin Cytom 76, 18-26, doi:10.1002/cyto.b.20439 (2009).

Koh, Y. G. et al. Mesenchymal stem cell injections improve symptoms of knee osteoarthritis. Arthroscopy 29, 748-755, doi:10.1016/j.arthro.2012.11.017 (2013). nucleated cells, CD34-positive cells and CFU-GM colonies in single bone marrow samples and bone marrow harvests derived from healthy children. Pediatr Hematol Oncol 31, 340-348, doi:10.3109/08880018.2013.874513 (2014).

Rezvani, A. R. et al. Impact of donor age on outcome after allogeneic hematopoietic cell transplantation. Biol Blood Marrow Transplant 21, 105-112, doi:10.1016/j.bbmt.2014.09.021 (2015). collection of PBSCs for allogeneic hematopoietic cell transplantation. Bone Marrow Transplant 46, 1296-1302, doi:10.1038/bmt.2010.310 (2011). 
3319 Civriz Bozdag, S., Bay, M., Ayyildiz, E., Topcuoglu, P. \& Ilhan, O. Older age and 332 capacity of colony forming unit in autologous peripheral derived hematopoietic cells. 333 Transfus Apher Sci 47, 113-116, doi:10.1016/j.transci.2012.05.011 (2012).

33410 de Windt, T. S., Bekkers, J. E., Creemers, L. B., Dhert, W. J. \& Saris, D. B. Patient 335 profiling in cartilage regeneration: prognostic factors determining success of treatment 336 for cartilage defects. Am J Sports Med 37 Suppl 1, 58S-62S, 337 doi:10.1177/0363546509349765 (2009).

33811 Kresnik, P. K., Krasna, M., Rozman, P., Vrtovec, B. \& Malicev, E. Collection and 339 immunoselection of CD34+ cells: the impact of age, sex, and diabetes in patients with $340 \quad$ chronic heart failure. Transfusion 56, 1792-1800, doi:10.1111/trf.13646 (2016).

34112 Oliver, K., Awan, T. \& Bayes, M. Single- Versus Multiple-Site Harvesting Techniques 342 for Bone Marrow Concentrate: Evaluation of Aspirate Quality and Pain. Orthop J Sports 343 Med 5, 2325967117724398, doi:10.1177/2325967117724398 (2017).

34413 Furuta, T. et al. Mesenchymal Stem Cell-Derived Exosomes Promote Fracture Healing 345 in a Mouse Model. Stem Cells Transl Med 5, 1620-1630, doi:10.5966/sctm.2015-0285 $346 \quad$ (2016).

34714 Terstappen, L. W., Huang, S., Safford, M., Lansdorp, P. M. \& Loken, M. R. Sequential 348 generations of hematopoietic colonies derived from single nonlineage-committed 349 CD34+CD38- progenitor cells. Blood 77, 1218-1227 (1991).

35015 Robinson, P. G. et al. Reporting of Mesenchymal Stem Cell Preparation Protocols and 351 Composition: A Systematic Review of the Clinical Orthopaedic Literature. Am J Sports $352 \quad$ Med 47, 991-1000, doi:10.1177/0363546518758667 (2019).

35316 Povsic, T. J. et al. Aging is not associated with bone marrow-resident progenitor cell 354 depletion. J Gerontol A Biol Sci Med Sci 65, 1042-1050, doi:10.1093/gerona/glq110 355 (2010). 
35617 El-Jawhari, J. J. et al. Enrichment and preserved functionality of multipotential stromal 357 cells in bone marrow concentrate processed by vertical centrifugation. Eur Cell Mater $358 \quad$ 40, 58-73, doi:10.22203/eCM.v040a04 (2020).

35918 Hegde, V. et al. A prospective comparison of 3 approved systems for autologous bone 360 marrow concentration demonstrated nonequivalency in progenitor cell number and 361 concentration. J Orthop Trauma 28, 591-598, doi:10.1097/BOT.0000000000000113 362 (2014).

36319 Hernigou, P. et al. Benefits of small volume and small syringe for bone marrow 364 aspirations of mesenchymal stem cells. Int Orthop 37, 2279-2287, doi:10.1007/s00264$365 \quad$ 013-2017-z (2013). 
FIGURE LEGEND

368 FIGURE 1 Scatter plot showing linear positive relationship between CD34+ cells (count/ $\mu$ l) 369 and leukocytes (count/ $\mu \mathrm{l})$ in bone marrow aspirate (BMA).

371 FIGURE 2 Scatter plot showing the relationship between age (years) and CD34+ cells 372 (count $/ \mu 1 / \mathrm{kg}$ body weight) in bone marrow (BM) aspirate.

374 FIGURE 3 Percentage of CD34+ cells of the leukocytes (count/ $\mu$ l) in bone marrow aspirate 375 according to the non-malignant diseases including autism (AUT), cerebral palsy (CP), spinal 376 cord injury (SCI), amyotrophic lateral sclerosis (ALS), neurodegenerative diseases

377 (NeuroDegen), muscle dystrophy (MD), and neurological diseases (NEURO) of children (237818 years, light grey) and adults (dark grey).

380 FIGURE 4 Scatter plot showing that the lower the CD34+ cells (count/ $\mu 1)$ in bone marrow 381 aspirate (BMA) the higher the concentration (times) of CD34+ cells (count/ $\mu \mathrm{l})$ in bone marrow 382 aspirate concentrate (BMAC) after centrifugation. 
Figures

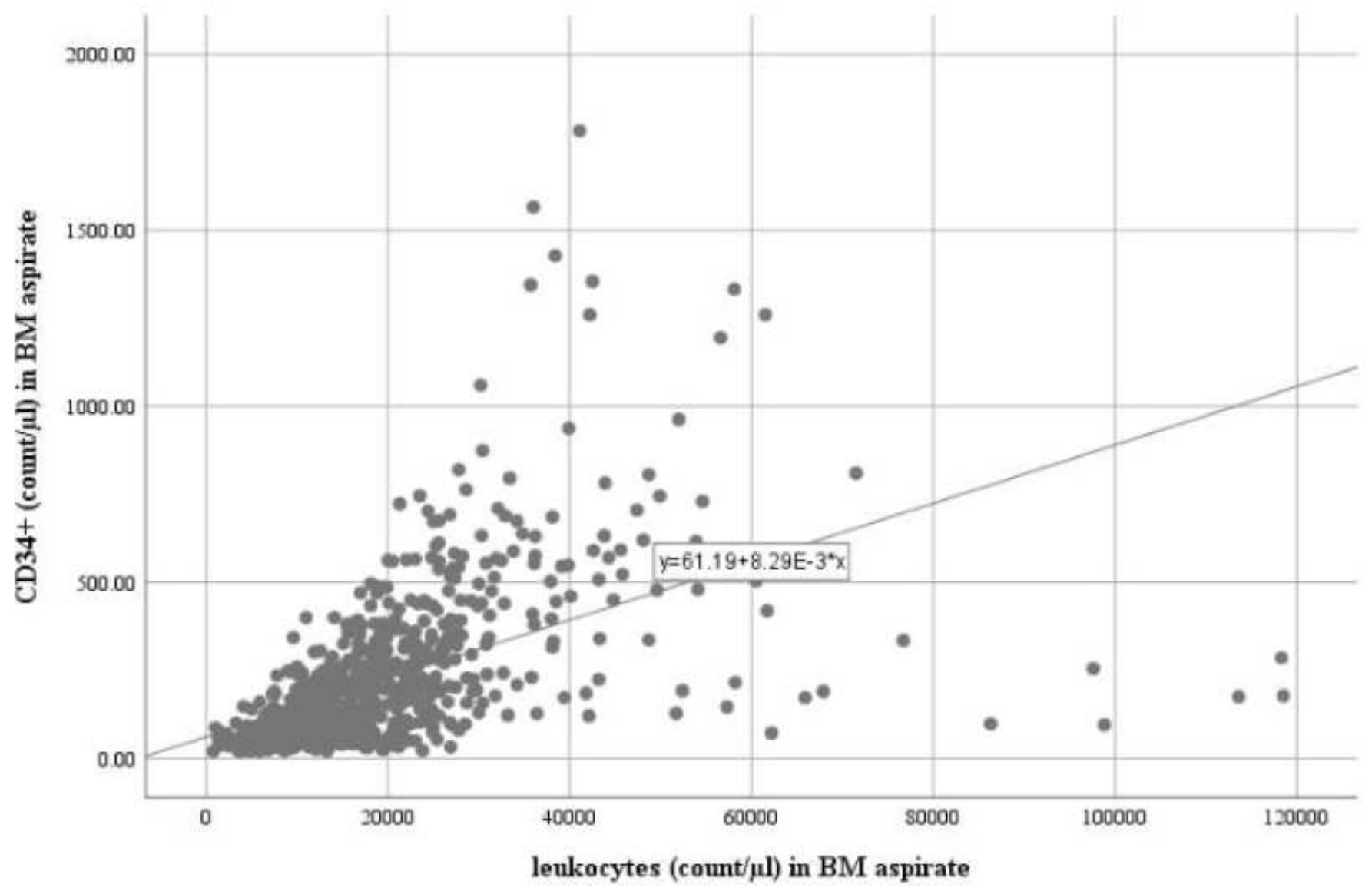

Figure 1

Scatter plot showing linear positive relationship between CD34+ cells (count/ $\mu \mathrm{l}$ ) and leukocytes (count/ $\mu \mathrm{l})$ in bone marrow aspirate (BMA). 


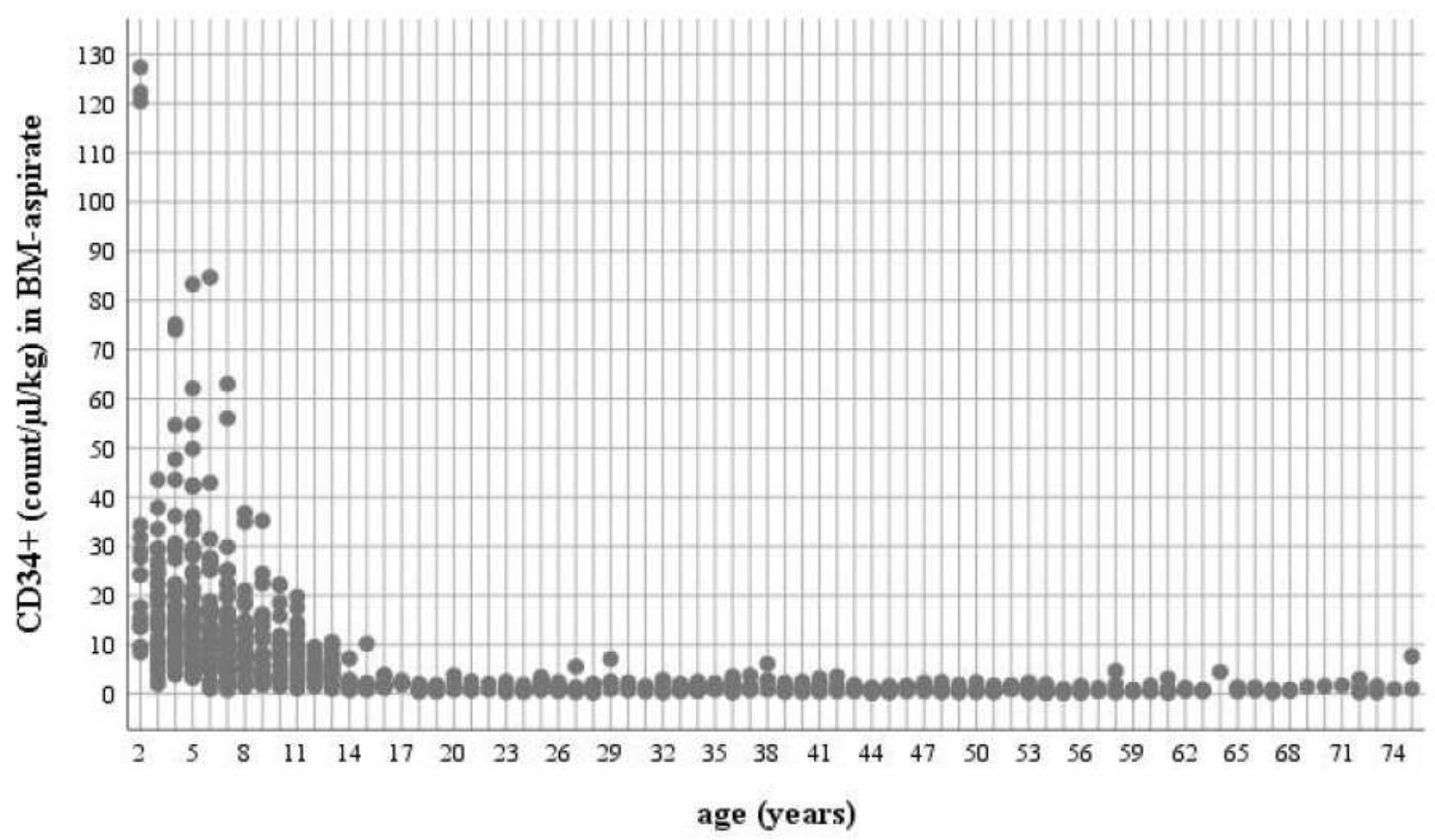

Figure 2

Scatter plot showing the relationship between age (years) and CD34+ cells (count $/ \mu \mathrm{l} / \mathrm{kg}$ body weight) in bone marrow (BM) aspirate. 


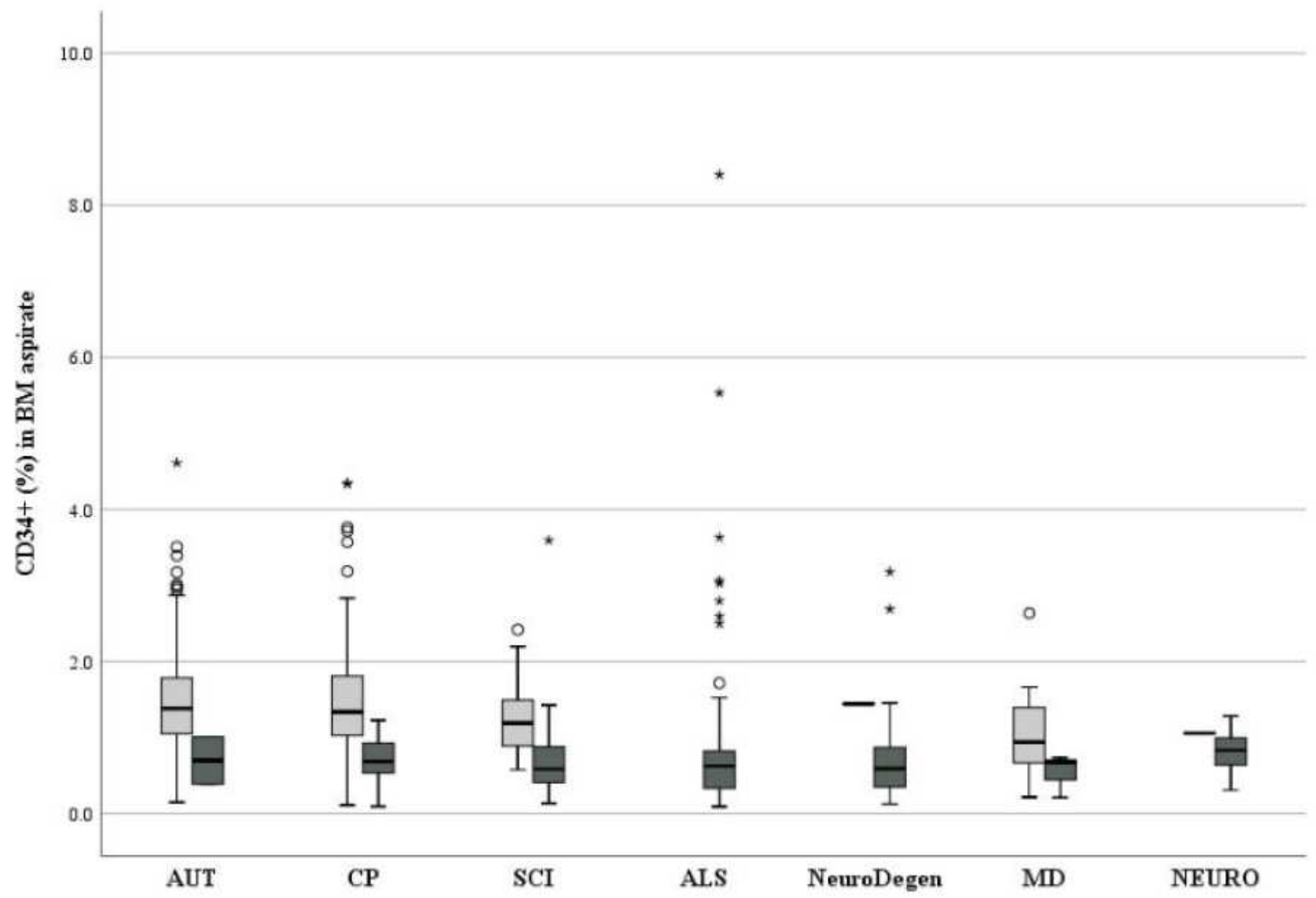

Figure 3

Percentage of CD34+ cells of the leukocytes (count/ $\mu \mathrm{l})$ in bone marrow aspirate according to the nonmalignant diseases including autism (AUT), cerebral palsy (CP), spinal cord injury (SCI), amyotrophic lateral sclerosis (ALS), neurodegenerative diseases (NeuroDegen), muscle dystrophy (MD), and neurological diseases (NEURO) of children (2-18 years, light grey) and adults (dark grey). 


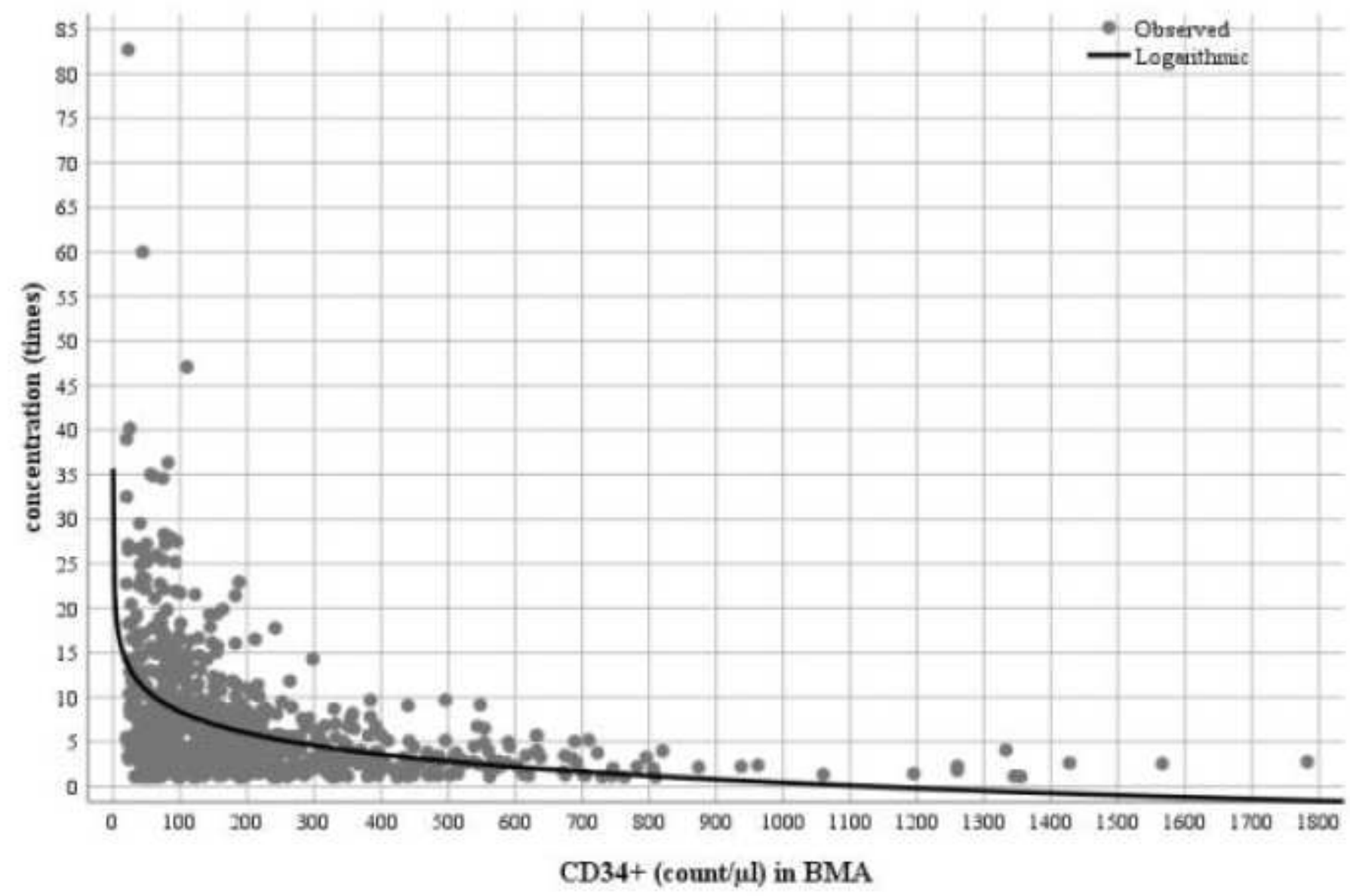

Figure 4

Scatter plot showing that the lower the CD34+ cells (count/ $\mu \mathrm{l})$ in bone marrow aspirate (BMA) the higher the concentration (times) of CD34+ cells (count/ $\mu \mathrm{l}$ ) in bone marrow aspirate concentrate (BMAC) after centrifugation.

\section{Supplementary Files}

This is a list of supplementary files associated with this preprint. Click to download.

- Table1.pdf 